\title{
Analisis respon peletakan vegetasi berdasarkan fungsi vegetasi terhadap kondisi tapak kawasan Kampus Unissula Semarang
}

\author{
Boby Rahman $1^{1^{*}}$ \\ 1. Prodi Perencanaan Wilayah dan Kota Universitas Islam Sultan Agung, Semarang, Indonesia \\ *E-mail: bobyrahman@unissula.ac.id
}

\begin{abstract}
Analysis of vegetation laying response based on vegetation function against the site conditions of the Semarang Unissula campus area. Green open spaces become an inseparable part in all campus environments. No exception at the Sultan Agung Islamic University (Unissula) campus in Semarang with one of the concepts being Islamic, Green, Ecology and Smart (IGES). More than 1,600 vegetations are embedded in the campus area of Unissula. The purpose of this study is to review how far vegetation is able to support (provide environmental comfort) as a place for teaching, learning and all activity. By using qualitative methodology and superimpose map analysis techniques, an analysis of the function of vegetation that has been planted on the condition of the campus site of Unissula. The result is that the response of vegetation planting has adjusted to the condition of the site of the Unissula campus, this response is in the form of planting a vegetation function on noise, pollution, circulation and aesthetics. The analysis also shows that the area covered by vegetation canopy reaches $23 \%$ of the total area, but when viewed in more depth the distribution of land cover covered with vegetation canopy covers the pedestrian circulation of each unit (building function) to the mosque as The meeting point of this activity shows that vegetation planning is not only based on a scale of size but can also go through the approaches of areas that are places and patterns of movement of human activities
\end{abstract}

Keywords: function response, laying vegetation, site

\section{Pendahuluan}

Unissula telah meng"ikon"kan untuk menjadi pendidikan unggul yang Islamic, Green, Eco, dan Smart (IGES) (Suaramerdeka, 2018). Menalaah makna green biasanya memberikan makna hijau atau sejuk dan teduh atau ruang terbuka yang ditanami oleh peneduh. Hal tersebut juga nampak pada kawasan Unissula kondisi eksisting sudah nampak hijau, berbagai jenis tanaman sudah ditanam di kawasan kampus Unissula, baik tanaman yang baru maupun tanaman yang sudah berumur lama. Namun untuk membentuk kawasan yang sejuk, teduh dan nyaman, perlu adanya kesesuaian tanaman vegetasi yang ditanam sesuai dengan kondisi dan fungsi kawasan. Setiap vegetasi mempunyai fungsi tertentu sesuai dengan keperluan. Fungsi vegetasi tumbuhan hijau memiliki berbagai manfaat untuk kawasan. Berbagai manfaat tumbuhan hijau dapat dikategorikan dalam 4 fungsi utama, yaitu : (1) fungsi ekologis; (2) fungsi estetis dan arsitektural; (3) fungsi ekonomi; dan (4) fungsi sosial (Widyastuti et al., 2013).

Di kawasan kampus Unissula terdapat kurang lebih ada 75 jenis vegetasi antara lain Akasia, Angsana, Asam Jawa, Asoka, Bambu, Belimbing, Bakau, Beringin, Bidara, Blimbing Wuluh, Bougenville, Buah Naga, Buah Tin, Bunga Sepatu, Cemara, Cordyline, Dadap, Dracaena, Elacis guineensist, Erpah bayam merah, Glodokan Tiang, Grass dianela, Jambu, Japanesse lauren, Jati, Jeruk, Kamboja, Karet, karsem, Kastanye, kedondong, Kelapa, Kelengkeng, Kemuning, Kersen, Ketapang, Kiara Payung, Kurma, Mahoni, Mangga, Melanding, Melati, Melinjo, Mimba, Nangka, Pakis Haji, Palem, Pepaya, Perdu Petai Cina, Pinang, Pisang, Pucuk merah, Puring, Queensland, rambutan, Randu, Rhapis, Ruellia Ungu, Salam Koja, Sambi, Sawo, Sengon, Sirsak, Srikaya, Sukun, Taberancamontana auva, Tanjung, Tin, Trambesi, Waru, Wuni dan Yucca. Dengan melihat sebaran jumlah jenis vegetasi yang ada, maka dapat diketahui bahwa komposisi fungsi vegetasi yang ada dikawasan adalah 612 batang vegetasi dengan fungsi peneduh, 298 vegetasi dengan fungsi pengarah, 84 batang vegetasi dengan fungsi penyerap polutan dan 620 batang/rumpun vegetasi dengan fungsi hias/estetika. 


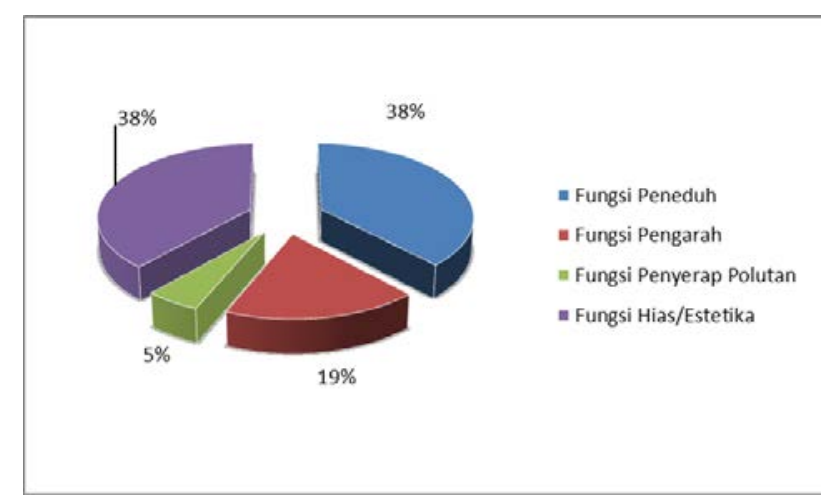

Gambar 1. Komposisi Vegetasi Berdasarkan Fungsi

(Survey Primer, 2019)

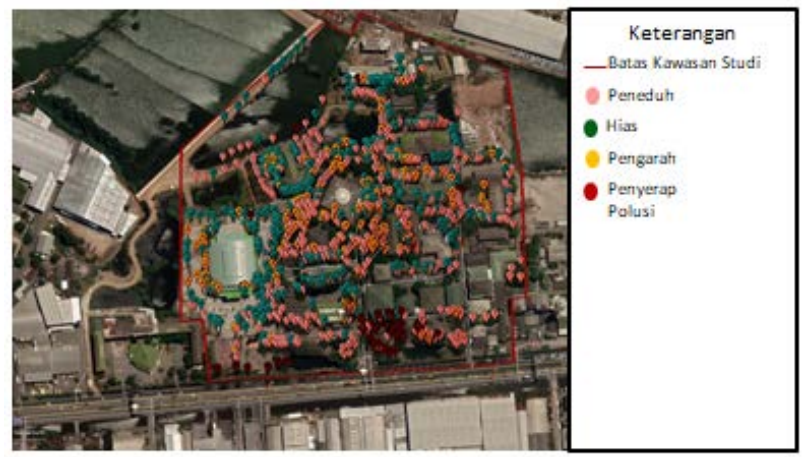

Gambar 2. Sebaran Vegetasi di Kawasan Penelitian

(Survey Primer dan Google Earth, 2019)

Dengan sebaran vegetasi dan identifikasi fungsi vegetasi, maka dilakukan analisis respon pemilihan vegetasi berdasarkan fungsi vegetasi terhadap kondisi tapak kawasan. Analisis ini tentunya juga tidak dapat lepas dari dua konsep kampus Unissula yaitu Islamic dan Green, melihat dua komponen tersebut maka penelitian terkait peletakan vegetasi ini menjadi penting karena meninjau seberapa jauh vegetasi mampu mendukung (memberikan kenyaman lingkungan) aktivitas "budaya akedemik Islam" dan menjadi laboratorium alam dalam perencanaan vegetasi terhadap gangguan kondisi tapak kawasan. Melalui penelitian diharapkan dapat memberikan suatu pandangan terkait peletakan vegetasi dan pemilihan vegetasi sesuai fungsi berdasarkan kondisi tapak.

\section{Metode}

Secara harfiah, metodologi adalah suatu kerangka pendekatan pola pemikiran dalam menyusun sebuah studi. Metodologi penelitian sendiri merupakan ilmu yang mempelajari tentang metoda-metoda penelitian, ilmu tentang alat-alat dalam penelitian (Muhadjir, 1996). Metodologi yang digunakan didalam penelitian ini adalah metodologi kualitatif, suatu metode untuk berusaha memahami dan menafsirkan makna suatu peristiwa interaksi tingkah laku manusia dalam situasi tertentu, penelitian yang menggunakan penelitian kualitatif bertujuan untuk memahami obyek yang diteliti secara mendalam untuk mengembangkan konsep sensitivitas pada masalah yang dihadapi (Gunawan, 2013). Pada penelitian ini, metode kualitatif digunakan untuk memahami obyek penelitian yaitu fungsi vegetasi didalam kawasan kampus Unissula dengan responnya terhadap realitas kondisi tapak lingkungan dan pemahaman akan satu atau lebih dari fenomena yang dihadapi didalam kawasan.

Teknik analisis yang digunakan didalam penelitian ini adalah superimpose atau tumpang tindih dari berbagai unit informasi di kondisi eksisting. Superimpose merupakan teknik penggabungan beberapa peta atau informasi kondisi spasial (Mariza, \& Puspitasari, 2017). Superimpose juga sering disebut teknik tumpang susun yang dapat digunakan sebagai sistem penanganan data untuk menggabungkan beberapa informasi yang diisyaratkan atau dengan mencocokan kriteria atau persyaratan yang dikehendaki dalam 
karakteristik penelitian (Wismarini \& Khristanto, 2016). Didalam penelitian ini, superimpose yang digunakan adalah data-data spasial terkait kondisi tapak kawasan dan vegetasi yang telah diidentifikasi fungsinya, sehingga dapat mengkaji apakah vegetasi yang ada sudah tepat secara fungsinya bila dianalisis dengan kondisi tapak kampus Unissula. Untuk alur penelitian yang telah dilaksanakan, dapat dilihat pada gambar 3.

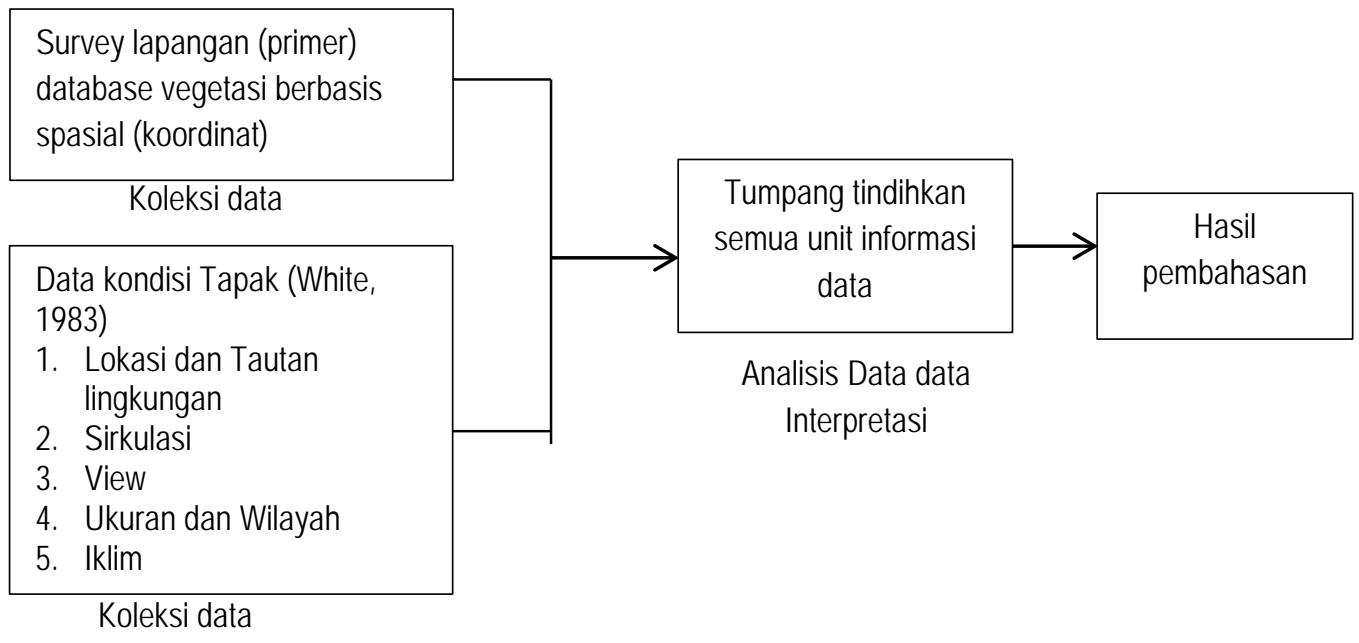

Gambar 3. Diagram Alur Penelitian

(Sumber: Hasil Interpretasi dan Analisis, 2019)

\section{Hasil dan Pembahasan}

\subsection{Lokasi dan Tautan Lingkungan}

Kawasan kampus Unissula berada di posisi strategis yaitu berada di jalan Nasional (Jalan Pantura) dan bersebelahan dengan Terminal Terboyo, sehingga potensial secara akses antar kota maupun antar provinsi. Namun berada di jalan nasional membuat kawasan berpotensi mengalami gangguan kebisingan dan polusi dari kendaraan besar seperti bus dan truk. Berdasarkan kondisi ini, maka terdapat respon penanaman vegetasi dengan fungsi penyerap polusi yaitu pohon trembesi yang menjadi salah satu pohon penyerap polusi terbaik (Sentiyaky et al., 2018), (Nurul, Anna, \& Sigit, 2013), (Widyarini \& Heddy, 2018).

Total terdapat 77 batang vegetasi yang menjadi pembatas hidup antara kawasan kampus Unissula dan Jalan Nasional. Selain trembesi, di lokasi ini ditanam pula vegetasi seperti pohon Akasia dan Angsana dengan kerapatan tinggi sebagai respon untuk mengurangi kebisingan dari jalan Nasional (Bachtiar, Afrianita, \& Zamzamy, 2018)(Azura, Erwin, \& Defrianto, 2015).
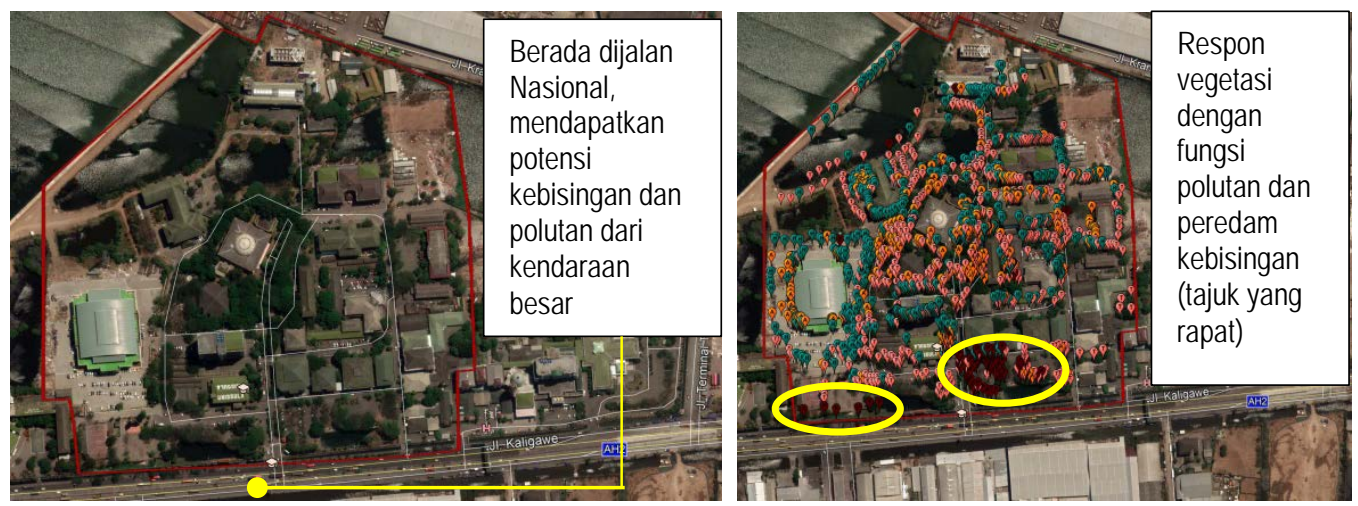

Gambar 4. Lokasi Berada di Jalan Nasional Di Respon Penanaman Vegetasi Penyerap Polutan dan Peredam Kebisingan

(Sumber: Hasil Analisis dan Survey Primer 2019) 


\subsection{Sirkulasi}

Kajian sirkulasi disini terbagi menjadi sirkulasi pejalan kaki dan kendaraan. Pada sirkulasi pejalan kaki kawasan kampus Unissula terpusat pada titik masjid. Hal ini terjadi karena kewajiban untuk sholat berjamaah di masjid pada saat dhuhur dan ashar, anjuran (sunah) sholat dhuha di pagi harinya, serta menjadikan masjid untuk wadah diskusi atau kajian mahasiswa sebagai bagian dari "Budaya Akademik Islam". Berdasarkan gambar $5 b$ maka dapat dianalisis bahwa respon fungsi vegetasi di jalur perjalan sirkulasi pejalan kaki dari setiap unit (fakultas, rektorat, perpustaan dan bidang lainnya) ke masjid, 91 \% (611 meter) telah tercover oleh fungsi vegetasi peneduh. Hal ini membuat pejalan kaki (mahasiswa maupun karyawan) merasa sejuk saat menuju ke masjid dari masing-masing unit. Sedangkan pada sirkulasi kendaraan, kampus Unissula menerapkan konsep sirkulasi satu arah. Dari hasil analisis gambar 5a maka dapat diketahui bahwa $51 \%$ (460 meter) tercover oleh fungsi vegetasi peneduh, dibeberapa sisi seperti persimpangan tidak ditanami sebagai respon untuk ruang bebas pandangan, begitu pula didepan unit-unit (fakultas, rektorat, perpustakaan dan lainnya) sebagai respon untuk memberikan view fasade bangunan dan informasi bangunan.
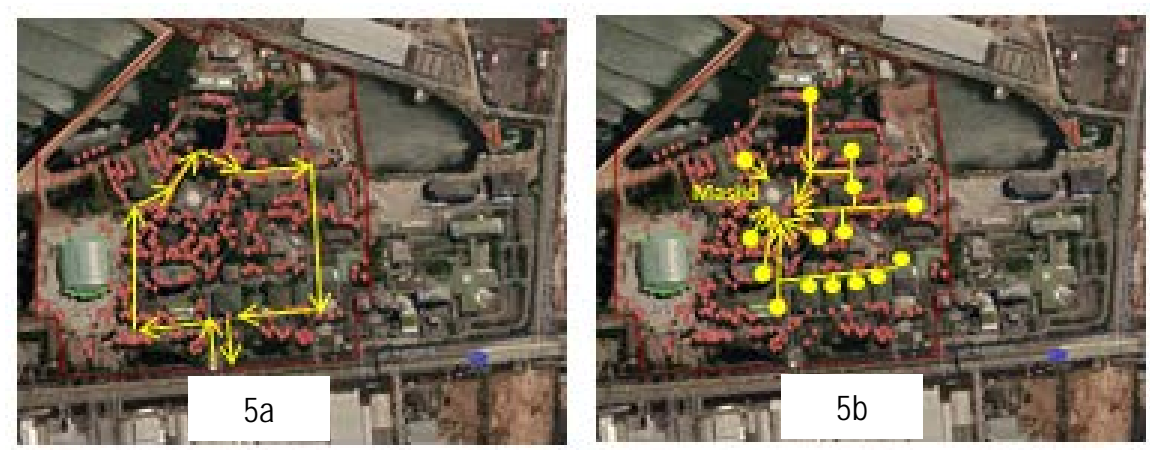

Gambar 5. Sirkulasi kendaraan dan pejalan kaki di respon melalui vegetasi peneduh dengan cover tutupan lahan (tajuk) mencapai $91 \%$ dan $51 \%$

(Sumber: Hasil Analisis dan Survey Primer 2019)
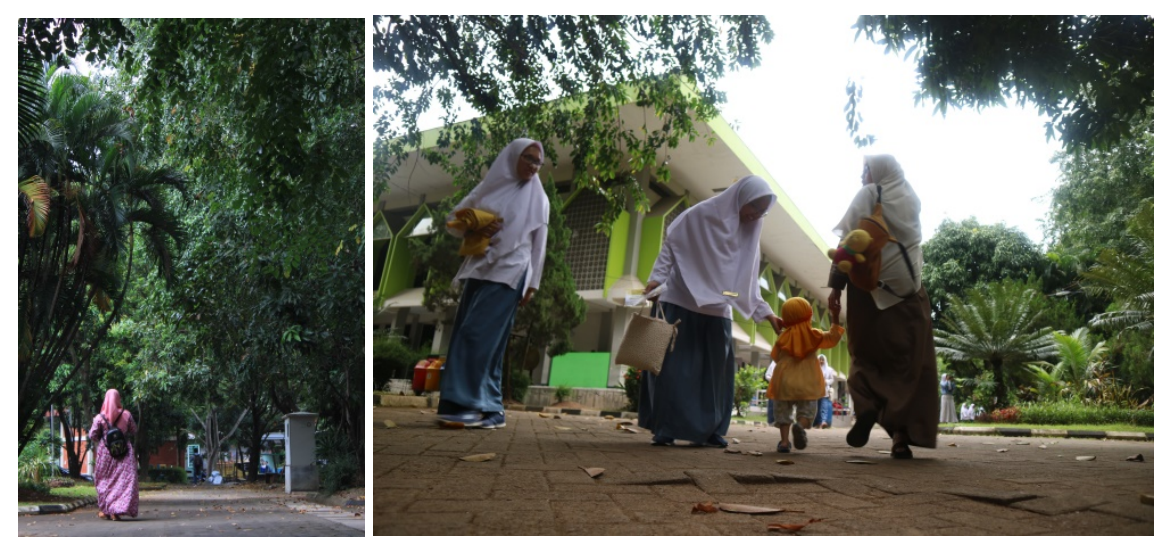

Gambar 6. Lokasi masjid di tengah kawasan kampus menjadi pusat kegiatan, dari setiap unit ke masjid dengan sirkulasi pejalan kaki terlindungi oleh teduhnya vegetasi peneduh

(Sumber: Dokumen Prodi PWK Unissula, 2018)

\subsection{View}

Konsep ruang terbuka hakikatnya akan memberikan tempat sosial seperti lokasi saling berinteraksi maupun hanya beristirahat (Allan, 2017). Konsep tersebutlah yang biasanya dihubungkan dengan peletakan view kawasan. View tapak berhubungan dengan respon vegetasi sebagai estetika atau bentuk tanaman hias. Mayoritas berada disekitar unit (fakultas, rektorat, perpustakaan dan lainnya) namun terdapat pula titik-titik meeting point orang-orang bersantai dan bersosialisasi di pelataran masjid, depan perpustakaan dan 
disamping kolam yang menjadi tempat banyak orang duduk berkumpul. Ketiga titik tersebut dapat dilihat pada gambar 7, respon vegetasi yang ditanam pada lokasi tersebut adalah vegetasi dengan fungsi estetika atau hias karena menjadi arah view dari aktivitas diluar ruangan. Dari hasil analisis maka pelatakan tanaman ini sudah sesuai dengan kondisi tapak dan perlu pengembangan dengan membuat pulau-pulau jalan sebagai taman kecil.

Pada kawasan kampus Unissula ditanam pula pohon yang identik dengan Islam. Tanaman yang sering ditemui pada kampus islami dan taman-taman yang berkonsep islam yaitu pohon kurma dan pohon tin (Alluthfi, 2018), (Walidaen, 2017). Penanaman pohon ini diletakkan di 3 tempat di gambar 7 sebagai salah satu respon konsep pengembangan kampus yang mengadopsi nilai-nilai islam.

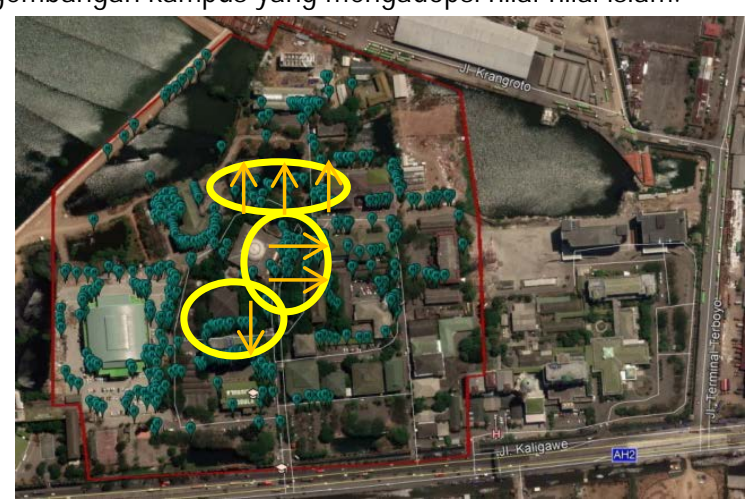

Keterangan

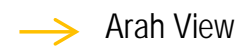

Titik Vegetasi Hias
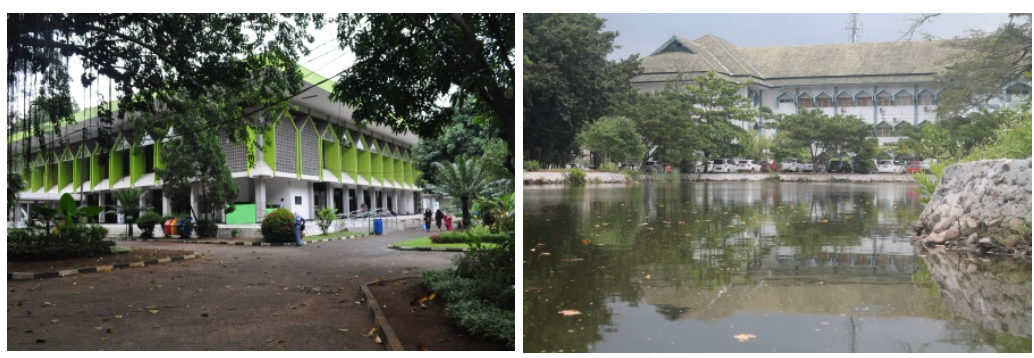

Gambar 7. Arah view masjid, perpustakaan dan kolam ditanami dengan vegetasi hias/estetika

(Sumber: Hasil Analisis dan Survey Primer 2019)

\subsection{Ukuran dan Wilayah}

Luas area kawasan penelitian kurang lebih 20,70 ha, luasan kawasan yang tertutupi oleh tajuk vegetasi mencapai 4,76 ha atau $23 \%$ dari seluruh kawasan teduh tertutupi oleh vegetasi peneduh bertajuk lebar dan rapat. Penggunaan ruang terbesar di kawasan penelitian adalah ruang terbuka non hijau berupa lapangan, parkiran, jalan dan kawasan non terbangun sebesar 8,19 ha atau 40\% dari luas kawasan. Untuk lebih jelasnya dapat dilihat pada tabel dibawah ini:

Tabel 1. Penggunaan Ruang di Kawasan Penelitian

\begin{tabular}{rlrr}
\hline No & Penggunaan Ruang & Luas (Ha) & Prosentase \\
\hline 1 & Bangunan & 3.88 & $19 \%$ \\
2 & Ruang Terbuka Biru (Air) & 3.82 & $18 \%$ \\
3 & Area Tutupan Lahan (Tajuk Vegetasi) & 4.76 & $23 \%$ \\
4 & RTNH (Parkiran, Jalan, Lapangan dII) & 8.19 & $40 \%$ \\
& Luasan Kawasan Penelitian & 20.70 & $100 \%$ \\
\hline
\end{tabular}

Sumber: Hasil Analisis dan Interpretasi Peta 2019

Arae tutupan Lahan (Tajuk Vegetasi) masih 23\%, namun area yang telah tertutup tajuk vegetasi merupakan area-area strategis meeting point dan pergerakan aktivitas manusia. Hal ini menunjukkan bahwa 
respon vegetasi untuk tutupan lahan bukan secara ukuran dan wilayah, namun lebih kepada pergerakan aktvitas manusianya atau pendekatan humanity activity.

\subsection{Iklim}

Berada di pesisir, membuat kondisi suhu menjadi lebih panas, namun di beberapa lokasi meeting point atau titik pertemuan terlindungi oleh vegetasi peneduh. Bahkan di titik halaman sekitar perpustakaan terlindungi dari sinar matahari dari pagi hingga sore oleh vegetasi peneduh yang rindang dan rapat, sehingga menimbulkan rasa sejuk dan nyaman mahasiswa saat beraktivitas disekitar perpustakaan. Respon vegetasi sangat baik karena membuat kondisi iklim teduh dari pagi hingga sore hari.

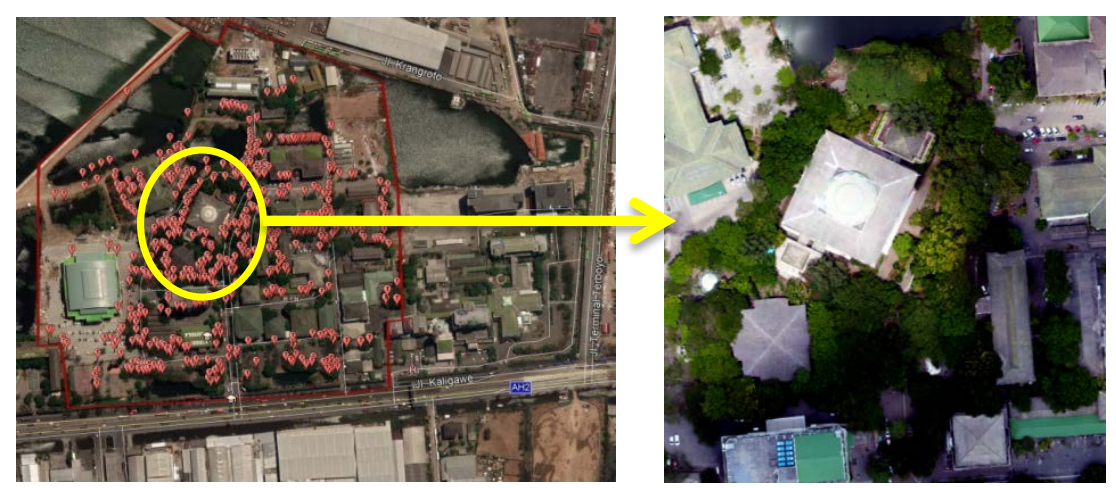

Gambar 8. Kawasan sekitar masjid dan perpustaakaan ter-cover oleh vegetasi peneduh dan rapat sehingga bernuansa teduh dan sejuk dari pagi hingga sore

(Sumber: Hasil Analisis dan Survey Primer 2019)

\section{Simpulan}

Kawasan Unissula mempunyai tautan kondisi wilayah yang cukup unik. Pertama berada dijalan nasional sehingga memiliki laju lintas harian kendaraan besar yang tinggi, sehingga secara fungsional perlu vegetasi peredam suara dan penyerap polusi. Konsep kawasan bangunan yang berdekatan sehingga ramah akan pejalan kaki, membutuhkan vegetasi dengan fungsi peneduh atau bertajuk tebal. Unissula dengan konsep perguruan islami, maka memerlukan konsep tanaman dengan fungsi estetis/arsitektur seperti tanaman berthemakan islam, hal tersebut membuat respon vegetasi hias dibeberapa titik berupa vegetasi Pohon Tin dan Kurma. Semua konsep tanaman fungsional tersebut akan meningkatkan kualitas kawasan yang berthemakan "green".

Ukuran wilayah yang tertutupi tajuk vegetasi hanya 23\%, namun bila ditinjau lebih dalam sebaran kawasan tutupan lahan yang ditutupi tajuk vegetasi berkumpul menutupi sirkulasi pejalan kaki dari masingmasing unit (fungsi bangunan) menuju Masjid sebagai meeting point kegiatan. Hal ini merupakan respon fungsi vegetasi terhadap kondisi sirkulasi pejalan kaki dan iklim kawasan yang tentunya akan memberikan rasa teduh dan sejuk bagi pejalan kaki dari setiap sudut unit. Hasil penelitian menunjukkan bahwa kondisi perencanaan vegetasi tidak hanya berdasarkan skala ukuran namun juga dapat melalui pendekatan kawasan-kawasan yang menjadi tempat dan pola pergerakan aktivitas mahasiswa maupun pegawai (humanity activity).

\section{Daftar Pustaka}

Allan, L. M., \& Karmilah, M. (2019). Pengaruh Aktivitas Ziarah Terhadap Ruang Publik Alun-Alun Studi Kasus: Kawasan Pemakaman Sunan Bonang. Jurnal Planologi, 14(2), 89-101.

Alluthfi, M. F. (2018). Pengaruh komposisi media tanam terhadap pembibitan tiga varietas tanaman tin (Ficus carica L.) (Doctoral dissertation, UIN Sunan Gunung Djati Bandung).

Azura, Erwin, \& Defrianto. (2015). Analisa Pengaruh Vegetasi Terhadap Tingkat Kebisingan Di Sepanjang Jalan Raya Pekanbaru-Bangkinang. JOM FMIPA, 2(1), 32-40.

Bachtiar, V. S., Afrianita, R., \& Zamzamy, A. (2018). Jurnal Dampak Evaluasi Tingkat Kebisingan Kawasan 
Selatan Universitas Negeri Padang. Jurnal Dampak, 15(1), 7-15.

Gunawan, I. (2013). Metode penelitian kualitatif. Jakarta: Bumi Aksara

Muhadjir, N (1996). Metodologi Penelitian Kualitatif. Edisi Ke-3. Rake. Sarasin. Yogyakarta.

Nur, A., Mariza, Z., \& Puspitasari, A. Y. (2017). Pada Aktivitas Penduduk Di Permukiman Studi Kasus]: Permukiman Mlaten Kota Semarang. Planologi, 14(2), 102-116.

Nurul, P., Anna, A. N., \& Sigit, A. A. (2013). Purnamasari, N., Anna, A. N., \& Sigit, A. A. (2016). Penentuan Prioritas Pengembangan Jalur Hijau Menggunakan Penginderaan Jauh Dan Sistem Informasi Geografis Di Kota Surakarta. Universitas Muhammadiyah Surakarta.

Sentiyaky, Rina, A. A. A., Fathurrahman, I., Yani, S., Mandasini, Nurjannah, \& Zara, S. (2018). ALAT Penyaring Karbon Monoksida Pada Knalpot Kendaraan Bermotor Dengan Menggunakan Adsorben Alami Ekstrak Daun Trembesi. Journal Of Chemical Process Engineering, 03(01), 38-42.

Walidaen, M. B., Utami, N. W. F., \& Yusiana, L. S. (2017). Perencanaan Taman Islam pada Lansekap Islamic Center Provinsi NTB. Jurnal Arsitektur Lansekap, 77-86.

White, E. T. (1983). Site Analysis: Diagramming Information for Architectural Design. Architectural Media, Tuscon, AZ.

Widyarini, P. A., \& Heddy, Y. B. S. (2018). Penilaian Estetika dan Fungsional Pohon Tepi Jalan Berdasarkan Persepsi Pengguna Jalan ( Studi Kasus[: JI ljen dan Jl Veteran Kota Malang ) Aesthetic and Functional Assessment of Roadside Trees Based on Street User Perceptions. Jurnal Produksi Tanaman, 6(9), 2320-2327.

Widyastuti (2013). Kesesuaian taman kota di surakarta berdasarkan konsep kota layak anak.

Wismarini, T. D., \& Khristanto, T. (2016). Implementasi Superimpose dalam Pemodelan Spasial Tingkat Rentan Banjir di Semarang. Jurnal Teknologi Informasi DINAMIK, 21(2), 124-138. 